\title{
Precautionary saving under many risks
}

\section{Donatella Baiardi, Marco Magnani \& Mario Menegatti}

\section{Journal of Economics}

ISSN 0931-8658

Volume 113

Number 3

J Econ (2014) 113:211-228

DOI 10.1007/s00712-013-0366-0
Vol. 113 No. 32014

\section{Journal of . Economics}

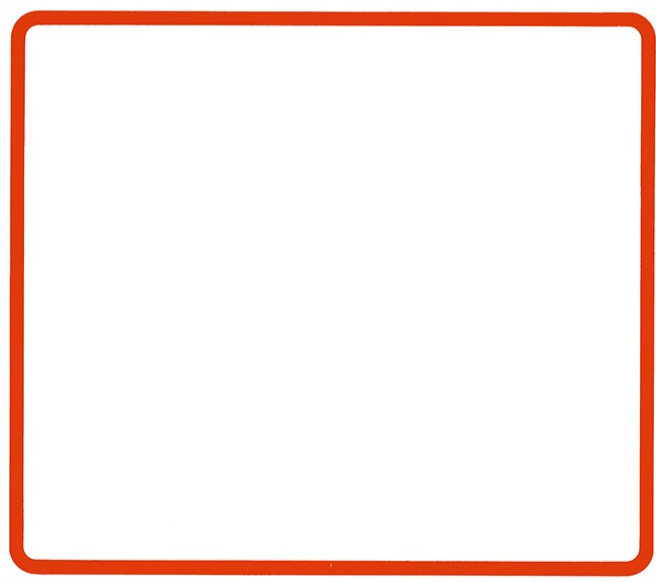

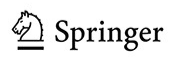


Your article is protected by copyright and all rights are held exclusively by SpringerVerlag Wien. This e-offprint is for personal use only and shall not be self-archived in electronic repositories. If you wish to self-archive your article, please use the accepted manuscript version for posting on your own website. You may further deposit the accepted manuscript version in any repository, provided it is only made publicly available 12 months after official publication or later and provided acknowledgement is given to the original source of publication and a link is inserted to the published article on Springer's website. The link must be accompanied by the following text: "The final publication is available at link.springer.com". 


\title{
Precautionary saving under many risks
}

\author{
Donatella Baiardi • Marco Magnani • \\ Mario Menegatti
}

Received: 11 April 2013 / Accepted: 19 August 2013 / Published online: 14 September 2013 (C) Springer-Verlag Wien 2013

\begin{abstract}
This paper studies precautionary saving when many small risks are considered. We first introduce two simultaneous risks: labor income and interest rate risks. We show that, in this context, sufficient conditions for precautionary saving are weaker than in similar models. Moreover, we find that, unlike previous literature, precautionary saving can occur in the case of negative covariance between the two risks and in the case of imprudence. We then extend our analysis to a three-risk framework, where a background risk is included. We derive sufficient conditions for precautionary saving which are interpreted in the light of the previous literature.
\end{abstract}

Keywords Precautionary saving - Labor income risk · Interest rate risk · Background risk $\cdot$ Prudence $\cdot$ Partial relative prudence

JEL Classification D81 E E21 D D11

\section{Introduction}

Precautionary saving theory studies the effects of uncertainty on consumption and saving choices. This theory starts with the seminal papers by Leland (1968), Sandmo

D. Baiardi

Department of Economics, Management and Statistics, University of Milan Bicocca, Milan, Italy e-mail: donatella.baiardi@unimib.it

M. Magnani · M. Menegatti $(\bowtie)$

Department of Economics, University of Parma, Via Kennedy 6, 43100 Parma, Italy

e-mail: mario.menegatti@unipr.it

M. Magnani

e-mail: marco.magnani@unipr.it 
(1970) and Drèze and Modigliani (1972), who show that if marginal utility is convex, labor income uncertainty generates an extra-saving called 'precautionary saving'. Kimball (1990) deepens the analysis of the convexity of marginal utility calling this feature of agent preferences 'prudence'. ${ }^{1}$ Other works, starting from Sandmo (1970) and Rothschild and Stiglitz (1971), investigate saving decisions when the interest rate (i.e. the return on saving) is uncertain. This literature shows that, in this case, the necessary and sufficient conditions for precautionary saving rely on the magnitude of the relative prudence index which must be higher than a threshold equal to $2 .^{2}$

During the last decade, precautionary saving has also been studied in a bivariate utility framework, where the second argument of the utility function represents a background variable, usually indicating health status or environmental quality. Assuming that this variable is random means introducing a background risk, which is flanked to the financial risk. ${ }^{3}$ In this field of research, Courbage and Rey (2007) and Menegatti (2009a) investigate precautionary saving, given specific assumptions on the distribution of the risky variables. Menegatti (2009b) analyzes the same problem in the presence of small risks, introducing the concept of 'two-source precautionary saving'. Finally, Denuit et al. (2011) study this issue when financial and background risks are positively correlated.

A different problem with many risks is recently analyzed by Li (2012), who studies jointly the two classical issues of precautionary saving by introducing together labor income and interest rate risks, under the assumption of positive quadrant dependence. Li finds that, in this framework, the necessary and sufficient conditions for positive precautionary saving require the partial relative prudence index to be larger than 2 .

The present paper reconsiders some of these issues with a twofold aim. We first re-examine the problem studied by Li (2012) without any assumption about the joint distribution of the two risks. However, in the line of a long tradition dated back to Pratt (1964), and following the recent contributions by Menegatti (2009b) and Wang and Gong (2012), we perform our analysis under the assumption of small risks. We show that, in this context, the sufficient conditions for precautionary saving are weaker than those derived by $\mathrm{Li}$ (2012). We propose different specifications of our results which focus on conditions concerning either agent preferences or the variances and the covariance of the two risks. Furthermore, we show that precautionary saving can also occur when the covariance between the two risks is negative and when the agent is imprudent. Finally the implications of our results for choices under risk of every size are investigated.

We then extend our analysis to a new problem characterized by the presence of three simultaneous sources of uncertainty: labor income risk, interest rate risk and background risk. To the best of our knowledge, this is the first time in the literature where precautionary saving is studied in this context. We derive a set of sufficient

\footnotetext{
1 Menegatti (2001) weakens the sufficient conditions about the positivity of the third derivative of the utility in the case where utility is defined over an unbounded domain.

2 Generalizations to the case of $n t h$-order risk changes are studied in Eeckhoudt and Schlesinger (2008) and Chiu et al. (2012).

3 The implication for risk aversion of a background risk in a two-argument utility framework is studied by Pratt (1988), Finkelshtain et al. (1999) and Courbage (2001).
} 
conditions, involving partial relative prudence, cross-prudence, correlation aversion and a new index measuring partial relative cross-prudence. We finally provide an interpretation of these conditions in the light of the previous literature.

The paper proceeds as follows. Section 2 presents the model and the three different sources of uncertainty (labor income risk, interest rate risk and background risk). Section 3 studies the case with labor income risk and interest rate risk. Section 4 extends the model introducing background risk. Section 5 concludes.

\section{The model}

We consider a two-period framework. We assume that the consumer has a Von Neumann-Morgenstern utility function $u(y, x)$ in period 0 and $v(y, x)$ in period 1 , where $y$ is wealth and $x$ is a non-financial variable as, for instance, health status (Grossman 1972; Bleichrodt et al. 2003; Rey and Rochet 2004; Eeckhoudt et al. 2007) or environmental quality (Ayong Le Kama and Schubert 2004; Xepapadeas 2005; Baiardi and Menegatti 2011). We denote by $u_{i}, u_{i j}, u_{i j t}\left(v_{i}, v_{i j}\right.$ and $v_{i j t}$, respectively) the first, second and third partial derivatives of $u$ ( $v$, respectively). Functions $u$ and $v$ are assumed to be strictly increasing and strictly concave with regard to each argument $\left(u_{1}>0, v_{1}>0, u_{11}<0, v_{11}<0\right)$, and three times continuously differentiable.

Given these assumptions, a typical formulation of the consumer decision problem in the certainty case is the following:

$$
\max _{s} u\left(y_{0}-s, x_{0}\right)+v\left(y_{1}+s(1+r), x_{1}\right)
$$

where $s$ denotes saving, $y_{0}, y_{1}$ is labor income in periods 0 and 1 , respectively, $x_{0}$, $x_{1}$ is the level of the background variable $x$ in periods 0 and 1 and $r \geq 0$ is the real interest rate. For the sake of simplicity, we assume in Problem (1), and from now on, that the intertemporal discount rate is embedded in the utility function $v(y, x)$.

Starting from this general framework, we study different problems where different sources of uncertainty are introduced: labor income risk, interest rate risk and background risk. We identify five distinct cases: (i) labor income risk; (ii) interest rate risk; (iii) labor income risk and interest rate risk; (iv) labor income risk and background risk; and finally (v) labor income risk, interest rate risk and background risk.

(i) Labor income risk

We denote by $\tilde{y}=y_{1}+\epsilon$ the uncertain labor income of period 1 where $\epsilon$ is a random variable such that $\mathbb{E}[\epsilon]=0$ and $\mathbb{E}(\tilde{y})=y_{1}$. In this case, the consumer decision problem is:

$$
\max _{s} u\left(y_{0}-s, x_{0}\right)+\mathbb{E}\left[v\left(\tilde{y}+s(1+r), x_{1}\right)\right] .
$$

This is the classical precautionary saving problem with labor income risk studied in the literature starting from Leland (1968), Sandmo (1970) and Drèze and Modigliani (1972). By comparing Problems (1) and (2), we obtain the well-known result that there is precautionary saving if the third derivative of the utility function is positive $\left(v_{111}>0\right)$. 


\section{(ii) Interest rate risk}

In this case we denote by $\tilde{r}=r+\eta$ the uncertain level of the interest rate, where $\eta$ is a random variable such that $\mathbb{E}[\eta]=0$ and $\mathbb{E}(\tilde{r})=r$. The model becomes:

$$
\max _{s} u\left(y_{0}-s, x_{0}\right)+\mathbb{E}\left[v\left(y_{1}+s(1+\tilde{r}), x_{1}\right)\right] .
$$

By comparing optimal choices in Problems (1) and (3), Sandmo (1970) and Rothschild and Stiglitz (1971) show that there is precautionary saving when the relative prudence index is greater than 2. ${ }^{4}$ Similar findings are obtained in different settings which do not deal with precautionary saving and in particular by Chiu and Eeckhoudt (2010) in the analysis of optimal labor supply under a stochastic wage rate, ${ }^{5}$ and by Baiardi and Menegatti (2011) in the study of optimal environmental policy under uncertainty.

(iii) Labor income risk and interest rate risk

When labor income and interest rate risks are simultaneously considered, our model becomes:

$$
\max _{s} u\left(y_{0}-s, x_{0}\right)+\mathbb{E}\left[v\left(\tilde{y}+s(1+\tilde{r}), x_{1}\right)\right]
$$

The necessary and sufficient conditions for precautionary saving, obtained by comparing Problems (1) and (4), are analyzed for the first time by $\mathrm{Li}$ (2012) under the assumption of positive quadrant dependence between the two risks. A brief summary of Li's results is given in Sect. 3 .

The first aim of this paper is to study Problem (4) removing the assumption of positive quadrant dependence. Following a long tradition in decision theory which starts from Pratt (1964), we consider a different limitation, focusing on the case of small risks.

(iv) Labor income risk and background risk

Precautionary saving can also be analyzed in a bivariate framework. As before, we denote by $\tilde{y}$ labor income risk and we introduce a background risk $\tilde{x}=x_{1}+v$ where $v$ is a random variable such that $\mathbb{E}[v]=0$ and $\mathbb{E}[\tilde{x}]=x_{1}$. In this case the consumer decision problem is the following:

$$
\max _{s} u\left(y_{0}-s, x_{0}\right)+\mathbb{E}[v(\tilde{y}+s(1+r), \tilde{x})]
$$

A recent strand of research in decision theory investigates precautionary saving in this setting. The comparison between Problems (1) and (5) is analyzed by Courbage and Rey (2007), Menegatti (2009a, 2009b) and Denuit et al. (2011), given different assumptions on the distribution of the two risks or in the case of small risks. These papers show that, in this framework, precautionary saving not only depends on prudence, but also on cross-prudence (which captures the effects on utility of the

\footnotetext{
${ }^{4}$ For a formal definition of the relative prudence index see Eq. (14).

5 In the same setting, Wang and Gong (2012) obtain a threshold equal to 2 for the partial relative prudence index.
} 
interaction between the two risks) and on the size and sign of the correlation between them.

A similar but alternative problem is the study of precautionary saving in the presence of a background risk together with a random interest rate. To our knowledge, this issue is new in the literature, but we do not analyze it. We prefer to consider the more general setting described below in Case (v).

(v) Labor income risk, interest rate risk and background risk

Finally, the three different risks may be considered simultaneously: labor income, interest rate and background risks. The consumer problem becomes in this case:

$$
\max _{s} u\left(y_{0}-s, x_{0}\right)+\mathbb{E}[v(\tilde{y}+s(1+\tilde{r}), \tilde{x})]
$$

The second aim of the present paper is to study precautionary saving in Problem (6) in the case of small risks. To the best of our knowledge, this issue is new to the literature. As in the previous case, our analysis will focus on the case of small risks.

Note finally that in all these problems the different risks are introduced only in the second period. This is a standard assumption in the literature on precautionary saving cited above and reflects the idea of distinguishing between 'the present' (first period) where everything is certain and 'the future' (second period) where there is uncertainty. A different possible framework could include the introduction of the background risk in both periods. For the purpose of comparability with previous literature, we examine this case in the Appendix rather than in the main sections of the paper.

\section{Labor income risk and interest rate risk}

In this section we examine the effects on precautionary saving of two different contemporaneous risks (labor income and interest rate risks). To this purpose, we compare optimal consumption and saving choices in Problems (1) and (4). In Problem (1), there is no risk, and the optimal level of saving $s^{\star}$ is defined by the following first-order condition:

$$
u_{1}\left(y_{0}-s^{\star}, x_{0}\right)=(1+r) v_{1}\left(y_{1}+s^{\star}(1+r), x_{1}\right)
$$

On the other hand, in Problem (4), there are two different risks (labor income risk and interest rate risk). The optimal level of saving $s^{\star \star}$ is determined by the first-order condition:

$$
u_{1}\left(y_{0}-s^{\star \star}, x_{0}\right)=\mathbb{E}\left[(1+\tilde{r}) v_{1}\left(\tilde{y}+s^{\star \star}(1+\tilde{r}), x_{1}\right)\right]
$$

The conditions ensuring positive precautionary saving are obtained by comparing Eqs. (7) and (8). It is easy to see that $s^{\star \star} \geq s^{\star}$ holds if and only if:

$$
\mathbb{E}\left[(1+\tilde{r}) v_{1}\left(\tilde{y}+s^{\star \star}(1+\tilde{r}), x_{1}\right)\right]-(1+r) v_{1}\left(y_{1}+s^{\star \star}(1+r), x_{1}\right) \geq 0
$$


In line with Menegatti (2009b), we consider the case of small risks. Given this assumption, we apply to $(1+\tilde{r}) v_{1}\left(\tilde{y}+s^{\star \star}(1+\tilde{r}), x_{1}\right)$ a second-order Taylor expansion around the point $\left(y_{1}, r\right)$ to obtain:

$$
\begin{aligned}
& (1+\tilde{r}) v_{1}\left(\tilde{y}+s^{\star \star}(1+\tilde{r}), x_{1}\right)=(1+r) v_{1}\left(y_{1}+s^{\star \star}(1+r), x_{1}\right) \\
& \quad+(1+r) v_{11}\left(y_{1}+s^{\star \star}(1+r), x_{1}\right)\left(\tilde{y}-y_{1}\right) \\
& +\left[v_{1}\left(y_{1}+s^{\star \star}(1+r), x_{1}\right)+s^{\star \star}(1+r) v_{11}\left(y_{1}+s^{\star \star}(1+r), x_{1}\right)\right](\tilde{r}-r) \\
& +\frac{1}{2}(1+r) v_{111}\left(y_{1}+s^{\star \star}(1+r), x_{1}\right)\left(\tilde{y}-y_{1}\right)^{2} \\
& +\frac{1}{2}\left[\left(s^{\star \star}\right)^{2}(1+r) v_{111}\left(y_{1}+s^{\star \star}(1+r), x_{1}\right)+2 s^{\star \star} v_{11}\left(y_{1}+s^{\star \star}(1+r), x_{1}\right)\right](\tilde{r}-r)^{2} \\
& +\left[s^{\star \star}(1+r) v_{11}\left(y_{1}+s^{\star \star}(1+r), x_{1}\right)+v_{11}\left(y_{1}+s^{\star \star}(1+r), x_{1}\right)\right]\left(\tilde{y}-y_{1}\right)(\tilde{r}-r) .
\end{aligned}
$$

Following Menegatti (2009b), we now substitute Eq. (10) in Inequality (9). After some algebra, we get:

$$
\begin{aligned}
& (1+r) v_{111}\left(y_{1}+(1+r) s^{\star \star}, x_{1}\right)\left\{\operatorname{var}[\tilde{y}]+\left(s^{\star \star}\right)^{2} \operatorname{var}[\tilde{r}]+2 s^{\star \star} \operatorname{cov}[\tilde{y}, \tilde{r}]\right\} \\
& +2 v_{11}\left(y_{1}+(1+r) s^{\star \star}, x_{1}\right)\left\{s^{\star \star} \operatorname{var}[\tilde{r}]+\operatorname{cov}[\tilde{y}, \tilde{r}]\right\} \geq 0
\end{aligned}
$$

where $\operatorname{var}[\tilde{y}]$ and $\operatorname{var}[\tilde{r}]$ are the variances of $\tilde{y}$ and $\tilde{r}$, respectively, and $\operatorname{cov}[\tilde{y}, \tilde{r}]$ is the covariance between $\tilde{y}$ and $\tilde{r}$. This clearly implies the following result:

Proposition 1 We have positive precautionary saving $\left(s^{\star \star}-s^{\star}\right)$ if and only if Inequality (11) holds.

Inequality (11) includes two terms which summarize in a compact condition the determinants of precautionary saving. In order to provide an interpretation for these two terms, we first note that:

$$
\operatorname{var}\left[\tilde{y}+s^{\star \star} \tilde{r}\right]=\operatorname{var}[\tilde{y}]+\left(s^{\star \star}\right)^{2} \operatorname{var}[\tilde{r}]+2 s^{\star \star} \operatorname{cov}[\tilde{y}, \tilde{r}]
$$

This implies that the first term in the left-hand side of Inequality (11) includes the variance of the sum of the two risks.

This variance is multiplied by $v_{111} \cdot{ }^{6}$ So, since the variance is positive, there is an incentive for a positive precautionary saving if $v_{111}>0$. This result is standard in the usual labor income risk framework as underlined in many papers (Leland 1968; Sandmo 1970; Drèze and Modigliani 1972; Kimball 1990).

As shown by Eeckhoudt and Schlesinger (2006) and Menegatti (2007), if $v_{111} \geq 0$, agent disutility due to uncertainty is decreasing in wealth. Hence, the agent is pushed to increase saving in order to transfer wealth to the second period where she faces uncertainty.

\footnotetext{
${ }^{6}$ For simplicity, we here denote as $v_{111}$ the third derivative with regard to the first argument of the bivariate utility function $v_{111}\left(y_{1}+(1+r) s^{\star \star}, x_{1}\right)$. A similar notation is adopted in the rest of the paper.
} 
We now examine the second term in Inequality (11). It depends on the sign of $v_{11}$ which is negative by the assumption of risk aversion. A risk averse agent dislikes uncertainty caused by risk. In our framework, however, when saving is positive $\left(s^{\star \star}>\right.$ 0 ), saving is itself a source of uncertainty; in fact by saving and investing in the financial market, each agent bears a risk whose size depends on the variance of the interest rate and is proportional to $s^{\star \star}$. Furthermore, the effects of random returns also interact with labor income risk. This interaction is captured by the covariance between the two risks $(\operatorname{cov}[\tilde{y}, \tilde{r}])$.

Note that in $\mathrm{Li}$ (2012) framework the assumption of positive quadrant dependence implies a positive covariance between the two risks. ${ }^{7}$ By the reasoning outlined above, this means that, given a positive saving, the term $\operatorname{cov}[\tilde{y}, \tilde{r}]$ always increases uncertainty. On the contrary, in our framework, covariance can be negative, implying that the interaction between the two risks may reduce uncertainty. By the reasoning above, this could push a risk averse agent to increase precautionary saving.

In order to see this, consider the second term in the left-hand side of Inequality (11). Given risk aversion, this term increases precautionary saving if:

$$
\operatorname{cov}[\tilde{y}, \tilde{r}] \leq-s^{\star \star} \operatorname{var}[\tilde{r}] .
$$

It is clear that, if saving is positive ( $s^{\star \star}>0$ ), Condition (13) requires covariance to be negative. In this case, however, covariance must also be sufficiently large in absolute value. This further element is necessary to ensure that the reduction in uncertainty related to the negative covariance exceeds the increase in uncertainty due to the variability of the returns on saving, represented by the term $-s^{\star \star} \operatorname{var}[\tilde{r}]$. A more detailed discussion on this point will be supplied in next subsection below Corollaries 5 and 6 .

Note finally that Condition (13) can also hold when saving is negative. Clearly, in this case, the agent is borrowing (instead of lending) at a random interest rate. This means that an increment in saving is a reduction in the amount borrowed, i.e. a reduction in risk exposure (represented by the term $-s^{\star \star} \operatorname{var}[\tilde{r}]$ ). This implies that the agent is pushed to increase saving not only when the covariance is negative but also when the covariance is positive but not too high. Only when $\operatorname{cov}[\tilde{y}, \tilde{r}]>-s^{\star \star} \operatorname{var}[\tilde{r}]$ does the increase in uncertainty due to the positive covariance exceed the reduction in uncertainty related to lower risk exposure. In this case the agent does not raise saving in face of uncertainty, so we do not have positive precautionary saving.

\subsection{Necessary conditions and sufficient conditions}

Starting from Inequality (11), we can now derive further results about necessary and sufficient conditions for precautionary saving. With this aim, it is useful to recall the definition of the partial relative prudence index, introduced for the first time by Choi et al. (2001) and Eichner and Wagener (2004a, 2004b) and used by Li (2012). The general formulation of the partial relative prudence index $P R P(X, m)$ is directly derived from that of the relative prudence index $R P(X, m)$. Following Li (2012), given a generic utility function $U(X+m)$,

\footnotetext{
7 See Li (2011).
} 


$$
R P(X, m)=-(X+m) \frac{U_{111}(X+m)}{U_{11}(X+m)} \quad \forall X+m>0
$$

and

$$
P R P(X, m)=-X \frac{U_{111}(X+m)}{U_{11}(X+m)} \quad \forall X>0, \forall m
$$

In our problem the partial relative prudence index is: ${ }^{8}$

$$
P R P=-s^{\star \star}(1+r) \frac{v_{111}\left(y_{1}+s^{\star \star}(1+r), x_{1}\right)}{v_{11}\left(y_{1}+s^{\star \star}(1+r), x_{1}\right)} .
$$

By Inequality (11) and Eq. (16), after simple algebra, we obtain that:

Proposition 2 In the presence of small risks,

$$
P R P \geq K
$$

where

$$
K=2 \frac{\left(s^{\star \star}\right)^{2} \operatorname{var}[\tilde{r}]+s^{\star \star} \operatorname{cov}[\tilde{y}, \tilde{r}]}{\operatorname{var}[\tilde{y}]+\left(s^{\star \star}\right)^{2} \operatorname{var}[\tilde{r}]+2 s^{\star \star} \operatorname{cov}[\tilde{y}, \tilde{r}]}=2 \frac{\left(s^{\star \star}\right)^{2} \operatorname{var}[\tilde{r}]+s^{\star \star} \operatorname{cov}[\tilde{y}, \tilde{r}]}{\operatorname{var}\left[\tilde{y}+s^{\star \star} \tilde{r}\right]} .
$$

is a necessary and sufficient condition to have a positive precautionary saving $\left(s^{\star \star} \geq s^{\star}\right)$.

Proposition 2 characterizes a threshold equal to $K$ for $P R P$ which depends on the distribution of the risky variables. This is new to the literature where the threshold for relative prudence (or partial relative prudence) always has an exact numerical value, usually 2. Studying the elements affecting $K$ allows us to derive different results about the conditions for precautionary saving. These are described in the rest of this subsection in Corollaries from 3 to 7 .

A first case which is worth studying is when $\operatorname{cov}[\tilde{y}, \tilde{r}] \geq 0$. This case allows us to compare our results directly with those obtained by $\mathrm{Li}(2012)$.

Corollary 3 In case of small risks, $\operatorname{cov}[\tilde{y}, \tilde{r}] \geq 0$ and $P R P \geq K$ where $K<2$ are sufficient for positive precautionary saving $\left(s^{\star \star} \geq s^{\star}\right)$.

Proof The proof is very simple. If $\operatorname{cov}[\tilde{y}, \tilde{r}] \geq 0$ then $\frac{\left(s^{\star \star}\right)^{2} \operatorname{var}[\tilde{r}]+s^{\star \star} \operatorname{cov}[\tilde{y}, \tilde{r}]}{\operatorname{var}[\tilde{y}]+\left(s^{\star \star}\right)^{2} \operatorname{var}[\tilde{r}]+2 s^{\star \star} \operatorname{cov}[\tilde{y}, \tilde{r}]}<$ 1 implying that $K<2$. Thus, by Proposition $2, P R P \geq K$ where $K<2$ and $\operatorname{cov}[\tilde{y}, \tilde{r}] \geq 0$ are sufficient for positive precautionary saving.

Li (2012) obtains that: ${ }^{9}$

\footnotetext{
${ }^{8}$ Note that, from now on, we drop the arguments of the functions $R P(X, m)$ and $P R P(X, m)$ for the sake of simplicity.

9 Lemma 4 is directly derived from Proposition 3.2 in Li (2012).
} 
Lemma 4 (Li 2012) Positive quadrant dependence between $\tilde{y}$ and $\tilde{r}$ and $P R P \geq 2$ are sufficient conditions for positive precautionary saving $\left(s^{\star \star} \geq s^{\star}\right)$.

Comparing Corollary 3 and Lemma 4, it is clear that our conditions, derived for the case of small risks, are weaker than those of Li. In fact, the threshold for PRP in Corollary 3 is smaller than that in Lemma 4. Moreover, positive covariance is a weaker condition than positive quadrant dependence. ${ }^{10}$ Also note that a threshold equal to 2 for relative prudence was found by Rothschild and Stiglitz (1971), who study the case where the agent bears only the interest rate risk. This implies that the level of prudence sufficient for positive precautionary saving in the case of two small positive covariating risks is also lower than that required in the one-risk framework.

Moreover, unlike Li (2012), we allow for circumstances where there is positive precautionary saving and the covariance between the two risks is negative. A first case where this may occur is presented in the corollary below, where no assumption about the sign of the covariance is made.

Corollary 5 In the presence of small risks, $\operatorname{var}\left[\tilde{y}_{1}\right] \geq\left(s^{\star \star}\right)^{2} \operatorname{var}[\tilde{r}]$ and $P R P(\tilde{y}, \tilde{r}) \geq$ $K$ where $K \leq 1$ are sufficient conditions to have $s^{\star \star} \geq s^{\star}$.

Proof Rewrite $K$ in Eq. (18) as:

$$
\begin{aligned}
& \frac{2\left(s^{\star \star}\right)^{2} \operatorname{var}[\tilde{r}]+2 s^{\star \star} \operatorname{cov}[\tilde{y}, \tilde{r}]+\operatorname{var}[\tilde{y}]-\operatorname{var}[\tilde{y}]}{\operatorname{var}[\tilde{y}]+\left(s^{\star \star}\right)^{2} \operatorname{var}[\tilde{r}]+2 s^{\star \star} \operatorname{cov}[\tilde{y}, \tilde{r}]} \\
& =\frac{\left(s^{\star \star}\right)^{2} \operatorname{var}[\tilde{r}]-\operatorname{var}[\tilde{y}]}{\operatorname{var}\left[\tilde{y}+s^{\star \star} \tilde{r}\right]}+1
\end{aligned}
$$

The condition $\operatorname{var}[\tilde{y}] \geq\left(s^{\star \star}\right)^{2} \operatorname{var}[\tilde{r}]$ guarantees that the first term in the equation above is negative hence implying $K \leq 1$ and establishing by Proposition 2 that $P R P \geq 1$ is sufficient for precautionary saving.

In Corollary 5 the precautionary saving motive depends again on the magnitude of the partial relative prudence index. Contrary to the previous findings, however, the partial relative prudence index is now compared with a lower threshold value ( $P R P \geq 1$ instead of $P R P \geq 2$ ). This is obtained at the cost of imposing an additional assumption over the distribution of the stochastic variables, which is not present in Proposition 2. In particular the lower threshold is sufficient for precautionary saving together with the further condition

$$
\operatorname{var}[\tilde{y}]-\left(s^{\star \star}\right)^{2} \operatorname{var}[\tilde{r}] \geq 0
$$

which requires that the volatility generated by the interest rate risk has to be smaller than that generated by the labor income risk.

A reference to a threshold equal to 1 for $P R P$ is new in the literature, and it appears only in three recent works. Gollier (2010) illustrates the role of this threshold in the analysis of the efficient discount rate. Wang and Gong (2012) show that a threshold

10 On this point see $\mathrm{Li}(2011)$. 
equal to 1 is one of the sufficient conditions ensuring that the presence of two small risks on non-labor income and on the wage rate increases labor supply. Finally Denuit and Rey (2013) show that this threshold characterizes a set of preferences where an increase in the correlation between two risks generates a smaller disutility if the agent is richer.

A possible interpretation of condition $P R P \geq 1$ in Corollary 5 is related to the reasoning supplied discussing Inequality (13). As explained there, in fact, an increment in saving has two effects in Period 1: it raises wealth but it also raises uncertainty since saving has a random return. The first effect pushes a prudent agent to increase saving while the second pushes a risk averse agent to reduce it. ${ }^{11}$ This implies that the first effect prevails only if relative prudence is sufficiently high, i.e. higher than 2 in Rothschild and Stiglitz (1971) and Li (2012) and higher than $K<2$ in Corollary 3. Given Condition (19), however, the increase in uncertainty due to an increment in saving is relatively small. This implies that the second effect described above is also small and thus that the first effect prevails even if partial relative prudence exceeds a lower threshold, i.e. a threshold equal to 1 instead of equal to 2 .

A further case which is worth studying is described in the following corollary.

Corollary 6 In the case of small risks, $v_{111} \geq 0$ and $\operatorname{cov}[\tilde{y}, \tilde{r}] \leq-s^{\star \star} \operatorname{var}[\tilde{r}]$ are sufficient conditions for positive precautionary saving $\left(s^{\star \star} \geq s^{\star}\right)$.

Proof Condition $v_{111} \geq 0$ ensures that the first term in the left hand side of Inequality (11) is positive and condition $\operatorname{cov}[\tilde{y}, \tilde{r}] \leq-s^{\star \star} \operatorname{var}[\tilde{r}]$ ensures that the second term is positive too. This implies that (11) holds and thus that $s^{\star \star} \geq s^{\star}$.

Corollary 6 does not introduce any condition on $P R P$, and only requires prudence $\left(v_{111} \geq 0\right)$ and $\operatorname{cov}[\tilde{y}, \tilde{r}] \leq-s^{\star \star} \operatorname{var}[\tilde{r}]$. Note that, when saving is positive, this last condition indicates that the covariance between the risks must be negative and sufficiently large. ${ }^{12}$ The interpretation of this result is again related to that of Inequality (13). Indeed, assuming $\operatorname{cov}[\tilde{y}, \tilde{r}] \leq-s^{\star \star} \operatorname{var}[\tilde{r}]$ means that saving and investing in the financial market reduces overall uncertainty. This is because the increase in uncertainty generated by the stochastic interest rate is more than compensated by the reduction in uncertainty, which follows from the negative covariance between labor income and interest rate risks. As a consequence, in this case, both prudence and risk aversion push the agent to increase saving. This implies that, given risk aversion, prudence alone is sufficient to have positive precautionary saving without any assumption on its level. ${ }^{13}$

Proposition 2 also has implications for necessary conditions. Note in particular that in Li (2012), given positive quadrant dependence, the necessary and sufficient condition for precautionary saving is $P R P \geq 2$, which requires, in turn, $v_{111} \geq 0$.

\footnotetext{
$11 \mathrm{Li}$ (2012) calls the first effect 'income effect' and the second 'substitution effect'. Rothschild and Stiglitz (1971, p. 69) refer to these two effects stating that: 'Intuition suggests that increased the uncertainty in the return on savings will either lower savings because"a bird in the hands is worth two in the bush " or raise it because a risk averse individual, in order to insure his minimum standard of life, saves more in face of increased uncertainty.'

12 Obviously the term 'large' refers to $|\operatorname{cov}[\tilde{y}, \tilde{r}]|$.

13 Note that a similar use of the reasoning below Inequality (13) can be made in the case where saving is negative and the agent is borrowing.
} 
This means that, in $\mathrm{Li}$ (2012), $v_{111} \geq 0$ is necessary for precautionary saving. Similarly, in Rothschild and Stiglitz (1971), who consider only the interest rate risk, the necessary and sufficient condition for precautionary saving is $R P \geq 2$. $R P \geq 2$ also requires $v_{111} \geq 0$, implying that $v_{111} \geq 0$ is necessary for precautionary saving. Finally, in the literature considering only labor income risk (Leland 1968; Sandmo 1970; Drèze and Modigliani 1972), the necessary and sufficient condition for precautionary saving is directly $v_{111} \geq 0$.

These results indicate that in the literature which studies labor income and interest rate risk, either separately or jointly, $v_{111} \geq 0$ is always a necessary condition for precautionary saving. Examining Proposition 2, we see instead that:

Corollary 7 In the case of small risks, $v_{111} \geq 0$ is not necessary for precautionary saving.

Proof If $\operatorname{cov}[\tilde{y}, \tilde{r}]<-s^{\star \star} \operatorname{var}[\tilde{r}]$ the second term in the left-hand side of Inequality (11) is positive. This implies that Inequality (11) can hold even if the first term in its left-hand side is negative. This implies in turn that $v_{111} \geq 0$ is not necessary for Condition (11) to hold.

Corollary 7 shows that, in our framework, we get for the first time a case where labor income and interest rate risks can generate precautionary saving even if the agent is imprudent. This may occur when the covariance between the two risks is negative and very large, that is, when the random return on saving reduces uncertainty.

\subsection{Necessary conditions for all risks}

Proposition 2 shows a necessary and sufficient condition for positive precautionary saving in the case of small risks. Since, in general, small risks are a subset of all risks, it is clear that this condition is also a necessary condition for positive precautionary saving for all risks, where all means risks of every size (i.e. both small risks and large risks considered together). We can thus write:

Proposition 8 The condition

$$
P R P \geq K
$$

where

$$
K=2 \frac{\left(s^{\star \star}\right)^{2} \operatorname{var}[\tilde{r}]+s^{\star \star} \operatorname{cov}[\tilde{y}, \tilde{r}]}{\operatorname{var}[\tilde{y}]+\left(s^{\star \star}\right)^{2} \operatorname{var}[\tilde{r}]+2 s^{\star \star} \operatorname{cov}[\tilde{y}, \tilde{r}]}=2 \frac{\left(s^{\star \star}\right)^{2} \operatorname{var}[\tilde{r}]+s^{\star \star} \operatorname{cov}[\tilde{y}, \tilde{r}]}{\operatorname{var}\left[\tilde{y}+s^{\star \star} \tilde{r}\right]}
$$

is necessary for positive precautionary saving $\left(s^{\star \star} \geq s^{\star}\right)$ for risks of every size.

The necessary condition in Proposition 8 defines a threshold level for $P R P$. This threshold clearly depends on the characteristics of the random variables describing risks and, in particular, on the assumptions on their joint distribution. For instance, as 
shown by Li (2012), when considering positive quadrant dependent risks, the threshold for $P R P$ is equal to 2. Similarly, as shown in Sect. 3.1, when we assume that the two risks positively covariate, the threshold is characterized by $K<2$. More generally, by examining Eq. (21), it is clear that $K<2$ when condition

$$
\operatorname{var}[\tilde{y}] \geq-s^{\star \star} \operatorname{cov}[\tilde{y}, \tilde{r}]
$$

is satisfied. Finally when condition

$$
-\operatorname{cov}[\tilde{y}, \tilde{r}]>s^{\star \star} \operatorname{var}[\tilde{r}]
$$

holds, then $K<0$ and Condition (20) is always satisfied for a prudent agent (i.e. when $\left.v_{111}>0\right)$.

These results provide a characterization of $K$ in some specific cases. They suggest that a more detailed analysis on how $K$ changes when the variances of the two risks and their covariance change could be of interest. This can be a fruitful avenue for future research but however lies beyond the scope of the present paper.

\section{Labor income risk, interest rate risk and background risk}

We now extend the analysis in the previous section by introducing a small background risk and studying a model with three contemporaneous sources of uncertainty (labor income, interest rate and background risks). Note that, in a different direction, this analysis complements Menegatti (2009b), who examines a setting with small labor income and background risks. Also note that we consider here a case where the background risk is introduced only in the second period. The introduction of background risks in both periods is studied in the Appendix.

We compare optimal choices in Problems (1) and (6). In the case of Problem (6), the optimal level of saving $\widehat{s}$ is determined by the following first-order condition:

$$
\mathbb{E}\left[(1+\tilde{r}) v_{1}(\tilde{y}+\widehat{s}(1+\tilde{r}), \tilde{x})\right]=u_{1}\left(y_{0}-\widehat{s}, x_{0}\right)
$$

Comparing Eqs. (7) and (22), it is clear that we have positive precautionary saving $\left(\widehat{s} \geq s^{\star}\right)$ if and only if:

$$
\mathbb{E}\left[(1+\tilde{r}) v_{1}(\tilde{y}+(1+\tilde{r}) \widehat{s}, \tilde{x})\right]-(1+r) v_{1}\left(y_{1}+(1+r) \widehat{s}, x_{1}\right) \geq 0
$$

As in Sect. 3, we apply a second-order Taylor expansion of $(1+\tilde{r}) v_{1}(\tilde{y}+\widehat{s}(1+\tilde{r}), \tilde{x})$ around the point $\left(y_{1}, r, x_{1}\right)$. We get that:

$$
\begin{aligned}
& (1+\tilde{r}) v_{1}(\tilde{y}+(1+\tilde{r}) \widehat{s}, \tilde{x})=(1+r) v_{1}\left(y_{1}+(1+r) \widehat{s}, x_{1}\right) \\
& \quad+(1+r) v_{11}\left(y_{1}+(1+r) \widehat{s}, x_{1}\right)\left(\tilde{y}-y_{1}\right) \\
& \quad+\left[v_{1}\left(y_{1}+(1+r) \widehat{s}, x_{1}\right)+(1+r) \widehat{s} v_{11}\left(y_{1}+(1+r) \widehat{s}, x_{1}\right)\right](\tilde{r}-r) \\
& \quad+(1+r) v_{12}\left(y_{1}+(1+r) \widehat{s}, x_{1}\right)\left(\tilde{x}-x_{1}\right)+\frac{1}{2}(1+r) v_{111}\left(y_{1}+(1+r) \widehat{s}, x_{1}\right)\left(\tilde{y}-y_{1}\right)^{2}
\end{aligned}
$$




$$
\begin{aligned}
& +\frac{1}{2}\left[2 \widehat{s} v_{11}\left(y_{1}+(1+\bar{r}) \widehat{s}, x_{1}\right)+(1+r)(\widehat{s})^{2} v_{111}\left(y_{1}+(1+r) \widehat{s}, x_{1}\right)\right](\tilde{r}-r)^{2} \\
& +\frac{1}{2}(1+r) v_{122}\left(y_{1}+(1+r) \widehat{s}, x_{1}\right)\left(\tilde{x}-x_{1}\right)^{2} \\
& +\left[v_{11}\left(y_{1}+(1+r) \widehat{s}, x_{1}\right)+(1+r) \widehat{s} v_{111}\left(y_{1}+(1+r) \widehat{s}, x_{1}\right)\right]\left(\tilde{y}-y_{1}\right)(\tilde{r}-r) \\
& +(1+r) v_{112}\left(y_{1}+(1+r) \widehat{s}, x_{1}\right)\left(\tilde{y}-y_{1}\right)\left(\tilde{x}-x_{1}\right) \\
& +\left[v_{12}\left(y_{1}+(1+r) \widehat{s}, x_{1}\right)+(1+r) \widehat{s} v_{112}\left(y_{1}+(1+r) \widehat{s}, x_{1}\right)\right](\tilde{r}-r)\left(\tilde{x}-x_{1}\right) .
\end{aligned}
$$

Adopting the same procedure of Sect. 3 we now substitute Eq. (24) in Eq. (23). After some algebra, we obtain the following condition:

$$
\begin{aligned}
& (1+r) v_{111}\left(y_{1}+(1+r) \widehat{s}, x_{1}\right)\left\{\operatorname{var}[\tilde{y}]+(\widehat{s})^{2} \operatorname{var}[\tilde{r}]+2 \widehat{s} \operatorname{cov}[\tilde{y}, \tilde{r}]\right\} \\
& \quad+2 v_{11}\left(y_{1}+(1+r) \widehat{s}, x_{1}\right)\{\widehat{s} \operatorname{var}[\tilde{r}]+\operatorname{cov}[\tilde{y}, \tilde{r}]\} \\
& \quad+(1+r) v_{122}\left(y_{1}+(1+r) \widehat{s}, x_{1}\right) \operatorname{var}[\tilde{x}] \\
& \quad+2(1+r) v_{112}\left(y_{1}+(1+r) \widehat{s}, x_{1}\right)\{\operatorname{cov}[\tilde{y}, \tilde{x}]+\widehat{s} \operatorname{cov}[\tilde{r}, \tilde{x}]\} \\
& \quad+2 v_{12}\left(y_{1}+(1+r) \widehat{s}, x_{1}\right) \operatorname{cov}[\tilde{r}, \tilde{x}] \geq 0
\end{aligned}
$$

where $\operatorname{var}[\tilde{x}]$ is the variance of $\tilde{x}, \operatorname{cov}\left[\tilde{y_{1}}, \tilde{x}\right]$ is the covariance between $\tilde{y}$ and $\tilde{x}$ and $\operatorname{cov}[\tilde{x}, \tilde{r}]$ is the covariance between $\tilde{x}$ and $\tilde{r}$. We have thus that:

Proposition 9 In the case of three small risks, Condition (25) is necessary and sufficient to have a positive precautionary saving $\left(\widehat{s} \geq s^{\star}\right)$.

\subsection{Necessary conditions and sufficient conditions}

Given these findings, we can draw new conclusions on the necessary conditions and on the sufficient conditions for precautionary saving. First, examining Condition (25), it is clear that:

Corollary 10 In the case of three small risks, $v_{111} \geq 0$ is not necessary for precautionary saving.

This result extends the conclusion derived in Corollary 7 for the two-risk case, showing that also in the three-risk framework, positive precautionary saving is compatible with imprudence.

We now consider the sufficient conditions for positive precautionary saving. Given the complexity of the possible interactions among the three risks, we limit our analysis to the special circumstance where the covariances among the risky variables are positive. In order to perform this analysis, starting from the definition of the partial relative prudence index in Eq. (15), we define a new partial relative prudence index, which involves second-order and third-order cross-derivatives of the utility function. We call this new index 'partial relative cross-prudence index' which, given a generic 
utility function $U(X+m, Z)$, can be defined as: ${ }^{14}$

$$
P R C P(X, m, Z)=-X \frac{U_{122}(X+m, Z)}{U_{12}(X+m, Z)} \quad \forall X>0, \quad \forall m, Z
$$

In our framework, dropping the arguments of the index as in Sect. 3.1, we have:

$$
P R C P=-(1+r) \widehat{s} \frac{v_{122}\left(y_{1}+\widehat{s}(1+r), x_{1}\right)}{v_{12}\left(y_{1}+\widehat{s}(1+r), x_{1}\right)} .
$$

Now, starting from Condition (25) and given Condition (18), we obtain:

Corollary 11 In the case of three small risks and assuming positive covariances between the random variables $\tilde{y}, \tilde{r}$ and $\tilde{x}$, the four conditions:

$$
\begin{aligned}
P R P \geq K \text { where } K & <2 \\
v_{122} & \geq 0 \\
v_{12} & \leq 0 \\
P R C P & \geq 1
\end{aligned}
$$

are sufficient for positive precautionary saving $\left(\widehat{s} \geq s^{\star}\right)$.

Proof By Corollary 3, Condition (28) ensures that the sum of the first two terms in Eq. (25) is positive. Condition (29) ensures that the third term in Eq. (25) is positive. We now have to prove that Conditions (30) and (31) imply that the sum of the last two terms in Eq. (25) are positive too. This occurs if:

$$
\begin{aligned}
& 2(1+r) v_{112}\left(y_{1}+(1+r) \widehat{s}, x_{1}\right)\{\operatorname{cov}[\tilde{y}, \tilde{x}]+\widehat{s} \operatorname{cov}[\tilde{r}, \tilde{x}]\} \\
& \quad+2 v_{12}\left(y_{1}+(1+r) \widehat{s}, x_{1}\right) \operatorname{cov}[\tilde{r}, \tilde{x}] \geq 0
\end{aligned}
$$

Since all covariances are positive and given Condition (30), Inequality (32) holds if:

$$
-(1+\tilde{r}) \widehat{s} \frac{v_{122}(\tilde{y}+\widehat{s}(1+\tilde{r}), \tilde{x})}{v_{12}(\tilde{y}+\widehat{s}(1+\tilde{r}), \tilde{x})} \geq \frac{\widehat{s} \operatorname{cov}[\tilde{r}, \tilde{x}]}{\operatorname{cov}[\tilde{y}, \tilde{x}]+\widehat{s} \operatorname{cov}[\tilde{r}, \tilde{x}]} .
$$

Condition (31) ensures that Inequality (33) holds.

Condition $P R P \geq K$ in Corollary 11 is directly derived from Corollary 3 and its interpretation is the same as that used in Sect. 3 .

Condition $v_{122} \geq 0$ in Corollary 11 is analogous to the standard condition $v_{111} \geq 0$ which, starting from Leland (1968), characterizes the precautionary saving motive in the case of labor income risk. The condition $v_{122} \geq 0$ is the homologous condition for background risk, which affects the second argument of the utility function instead

\footnotetext{
14 The concept of 'cross prudence', introduced by Eeckhoudt et al. (2007), is associated with the sign of the third order cross derivatives of the utility function $v_{122}$. However, to our knowledge, the index in Eq. (26) is studied here for the first time.
} 
of the first one. This conclusion is confirmed by a recent result by Eeckhoudt et al. (2007, Sect. 5.2), who show that $v_{122} \geq 0$ is the necessary and sufficient condition for precautionary saving in the case where an agent only bears a background risk. ${ }^{15}$ Eeckhoudt et al. (2007) call this condition 'cross-prudence in wealth'. An interpretation of it can be derived by Menegatti (2007). Following Menegatti (2007), $v_{122} \geq 0$ is the condition ensuring that an higher wealth reduces the disutility due to the presence of a background risk. This pushes the agent to raise saving in order to increase wealth in the period where she bears the background risk (the second period).

Conditions $v_{12} \leq 0$ and $P R C P \geq 1$ need to be analyzed together. First note that, unlike $v_{11}$ which is usually assumed to be negative, $v_{12}$ is a second-order derivative of the utility function whose sign cannot be easily determined a priori. ${ }^{16}$ Eeckhoudt et al. (2007, Sect. 3.1), provide an interpretation of condition $v_{12} \leq 0$ in a risky framework. They call this feature of preferences 'correlation aversion' and show that it indicates that an agent dislikes circumstances where the negative outcomes of different risks occur together, i.e. she dislikes risks to be positively correlated.

Consider now the result by Denuit and Rey (2013) cited in Sect. 3. Denuit and Rey (2013) show that the condition $P R P \geq 1$ ensures that an increase in the correlation between two risks, which both affect wealth, generates a lower disutility if the level of wealth is higher (i.e. the agent is richer). In the present framework, where we consider two financial risks and a background risk, which influences a different argument of the utility function, the homologous of the previous condition is clearly $P R C P \geq 1$. This implies in turn that correlation aversion $v_{12} \leq 0$ and $P R C P \geq 1$ together indicate that an agent dislikes the positive correlation between financial risks and background risk and that the disutility caused by an increase in this correlation is lower if the agent has higher wealth. These conclusions show the reason why these conditions favor precautionary saving: when they both hold, the agent is pushed to increase saving since she prefers to increase wealth in the period where she faces the positive correlation between financial risks and background risk (the second period), in order to reduce the disutility caused by this correlation.

\section{Conclusion}

This paper studies optimal consumption and saving choices in a two-period model where different small risks are introduced together.

We start by analyzing the case of two small financial risks: labor income risk and interest rate risk. Various results are provided. First, unlike the previous literature, we provide a condition on partial relative prudence which does not refer to an exact numerical threshold but depends on the distribution of the risky variables. We then compare our results with those of Li (2012), who studies the same problem without introducing any assumption on risk size but assuming positive quadrant dependence between risks. We show that, in the case of small risks, the sufficient conditions for

\footnotetext{
15 An analogous role for the condition $v_{122} \geq 0$ in a two-risk framework is found by Menegatti (2009b) and, in a different context, by Baiardi and Menegatti (2011) who study optimal environmental policies.

16 A detailed discussion about the sign of this derivative is provided by Rey and Rochet (2004).
} 
positive precautionary saving are weaker than in Li (2012) framework. Furthermore, unlike $\mathrm{Li}$, we provide sufficient conditions for positive precautionary saving in the case of negative covariance between the two financial risks. We also derive an alternative set of sufficient conditions which weaken the requirement on the size of the relative prudence index, and we study a case where prudence alone ensures positive precautionary saving without any assumption on its level. We provide economic interpretations for all these sets of conditions. Furthermore, we show that, unlike the previous literature, our framework also allows for positive precautionary saving when the agent is imprudent. Finally, we investigate the implications of our results for the necessary condition for positive precautionary saving for risks of every size.

We then introduce an additional source of uncertainty, and analyze a framework, to our knowledge never previously examined, where the agent contemporaneously faces three small risks: labor income risk, interest rate risk and a background non-financial risk. In this context, we derive a set of sufficient conditions for positive precautionary saving, including those obtained in the two-risk framework and some others. The new conditions involve the so-called 'cross-prudence in wealth' and 'correlation aversion', and a threshold level for an index of 'partial relative cross-prudence', introduced here for the first time. We finally provide an interpretation of the elements favoring positive precautionary saving described by these conditions in the light of recent literature on decision-making under uncertainty.

\section{Appendix}

In this Appendix we consider a modification of Problem 6 where background risk is introduced in both first and second periods. The framework is the same as Problem 6 except for the introduction of the stochastic term $\tilde{x_{0}}=x_{0}+\psi$, where $\psi$ is a random variable such that $\mathbb{E}[\psi]=0$ and $\mathbb{E}\left[\tilde{x_{0}}\right]=x_{0}$. The consumer decision problem thus becomes:

$$
\max _{s} \mathbb{E}\left[u\left(y_{0}-s, \tilde{x_{0}}\right)\right]+\mathbb{E}[v(\tilde{y}+s(1+\tilde{r}), \tilde{x})]
$$

The optimal level of saving $\breve{s}$ is thus determined by the first-order condition:

$$
\mathbb{E}\left[(1+\tilde{r}) v_{1}(\tilde{y}+\check{s}(1+\tilde{r}), \tilde{x})\right]-\mathbb{E}\left[u_{1}\left(y_{0}-\check{s}, \tilde{x_{0}}\right)\right]=0
$$

The condition which ensures positive precautionary saving is obtained by comparing Eqs. (7) and (35). It is clear that, since $u_{11}<0$ and $v_{11}<0, \check{s} \geq s^{\star}$ holds if and only if

$$
\begin{aligned}
& \mathbb{E}\left[(1+\tilde{r}) v_{1}(\tilde{y}+\check{s}(1+\tilde{r}), \tilde{x})\right]-(1+r) v_{1}\left(y+\check{s}(1+r), x_{1}\right) \\
& \quad+u_{1}\left(y_{0}-\check{s}, x_{0}\right)-\mathbb{E}\left[u_{1}\left(y_{0}-\check{s}, \tilde{x_{0}}\right)\right] \geq 0
\end{aligned}
$$

Computations similar to those in Sect. 4 yield: 
Corollary 12 In the case of small labor income and interest rate risks in the second period ( $\tilde{y}$ and $\tilde{r}$, respectively) and small background risks in both first and second periods ( $\tilde{x}_{0}$ and $\tilde{x}$, respectively) and assuming positive covariances between the random variables $\tilde{y}, \tilde{r}$ and $\tilde{x}$, the five Conditions (28), (29), (30) and (31) and

$$
u_{122} \leq 0
$$

are sufficient to have positive precautionary saving $\left(\breve{s} \geq s^{\star}\right)$.

Proof As in Corollary 11, Conditions (28), (29), (30) and (31) ensure that the difference between the first and the second terms in the left-hand side of Inequality (36) is positive. By Jensen's inequality, Condition (37) ensures that the difference between the third and the fourth terms in the left-hand side of Inequality (36) is positive too. All the conditions together thus ensure that Inequality (36) holds.

The first four conditions in Corollary 12 are the same as Corollary 11 and their interpretation is analogous to that in Sect. 4. Condition (37), on the other hand, is new and is directly related to the introduction of a background risk in the first period. As Condition (29) indicates cross-prudence in wealth in period 2, Condition (37) indicates cross-imprudence in wealth in period 1. Its interpretation is thus straightforward. In presence of a background risk in the second period, the agent is pushed to increase saving if her disutility due to the background risk is lower when second-period wealth is higher. This is what cross-prudence in wealth in second period guarantees. Similarly, when we also have a background risk in first period, this risk pushes the agent to increase saving (and thus to reduce wealth in the first period) if the disutility due to the background risk is lower when first-period wealth is lower. This is exactly what is ensured by cross-imprudence in first period.

\section{References}

Ayong Le Kama A, Schubert K (2004) Growth, environment and uncertain future preferences. Environ Res Econ 28:31-53

Bleichrodt H, Crainich D, Eeckhoudt L (2003) Comorbidities in cost benefit analysis of health care. J Publ Econ 87:2399-2406

Baiardi D, Menegatti M (2011) Pigouvian tax, abatement policies and uncertainty on the environment. J Econ 103:221-251

Chiu HW, Eeckhoudt L (2010) The effects of stochastic wages and non-labor income on labor supply: update and extensions. J Econ 100:69-83

Chiu HW, Eeckhoudt L, Rey B (2012) On relative and partial risk attitudes: theory and implications. Econ Theory 50:151-167

Choi G, Kim I, Snow A (2001) Comparative statics predictions for changes in uncertainty in the portfolio and savings problems. Bull Econ Res 53:61-72

Courbage C (2001) On bivariate risk premia. Theory Decis 50:29-34

Courbage C, Rey B (2007) Precautionary saving in the presence of other risks. Econ Theory 32:417-424

Denuit M, Eeckhoudt L, Menegatti M (2011) Correlated risks, bivariate utility and optimal choices. Econ Theory 46:39-54

Denuit M, Rey B (2013) Benchmark values for higher order coefficients of relative risk aversion. Theory Dec 1-14

Drèze J, Modigliani F (1972) Consumption decision under uncertainty. J Econ Theory 5:308-335

Eeckhoudt L, Rey B, Schlesinger H (2007) A good sign for multivariate risk taking. Manag Sci 53:117-124 
Eeckhoudt L, Schlesinger H (2006) Putting risk in its proper place. Am Econ Rev 96:280-289

Eeckhoudt L, Schlesinger H (2008) Changes in risk and the demand for savings. J Monet Econ 55:1329_ 1336

Eichner T, Wagener A (2004a) Relative risk aversion, relative prudence, and comparative statics under uncertainty: the case of $(\mu, \sigma)$-preferences. Bull Econ Res 56:159-170

Eichner T, Wagener A (2004b) Insurance demand, the elasticity of risk aversion, and relative prudence: a further result. OR Spectrum 26:441-446

Finkelshtain I, Kella O, Scarsini M (1999) On risk aversion with two risks. J Math Econ 31:239-250

Gollier C (2010) Discounting, inequalities and economic convergence. CESifo working paper, no 3262

Grossman M (1972) On the concept of health capital and demand for health. J Polit Econ 80:223-255

Kimball MS (1990) Precautionary savings in the small and in the large. Econometrica 58:53-73

Leland H (1968) Saving and uncertainty: the precautionary demand for saving. Q J Econ 82:465-473

Li J (2011) The demand for a risky asset in the presence of a background risk. J Econ Theory 146:372-391

Li J (2012) Precautionary saving in the presence of labor income and interest rate risks. J Econ 106:251-266

Menegatti M (2001) On the conditions for precautionary saving. J Econ Theory 98:189-193

Menegatti M (2007) A new interpretation for the precautionary saving motive: a note. J Econ 92:275-280

Menegatti M (2009a) Precautionary saving in the presence of other risks: a comment. J Econ 39:473-476

Menegatti M (2009b) Optimal saving in the presence of two risks. J Econ 96:277-288

Pratt JW (1964) Risk aversion in the small and in the large. Econometrica 32:122-136

Pratt JW (1988) Aversion to one risk in the presence of others. J Risk Uncertain 1:395-413

Rey B, Rochet J (2004) Health and wealth: how do they affect individual preferences? Geneva Pap Risk Insur Theory 29:43-54

Rothschild M, Stiglitz J (1971) Increasing risk II: economic consequences. J Econ Theory 3:66-84

Sandmo A (1970) The effect of uncertainty on saving decisions. Rev Econ Stud 37:353-360

Wang J, Gong P (2012) Labor supply with stochastic wage rate and non-labor income uncertainty. J Econ 109:41-55

Xepapadeas A (2005) Economic growth and the environment. In: Handbook of environmental economics, vol 3, Chap 23. Elsevier, Amsterdam, pp 1219-1271 